\title{
Reoperative Sternotomy is Associated with Increased Mortality after Heart Transplantation
}

\author{
Timothy J. George, MD1, Claude A. Beaty, MD1, Gregory A. Ewald, MD², Stuart D. Russell, \\ MD ${ }^{3}$, Ashish S. Shah, MD ${ }^{1}$, John V. Conte, MD², Glenn J. Whitman, MD ${ }^{1}$, and Scott C. \\ Silvestry, MD ${ }^{4}$ \\ ${ }^{1}$ Division of Cardiac Surgery, Johns Hopkins Medical Institutions, Baltimore, MD \\ ${ }^{3}$ Division of Cardiology, Johns Hopkins Medical Institutions, Baltimore, MD \\ 2Division of Cardiovascular Diseases, Washington University School of Medicine, St. Louis, MO \\ ${ }^{4}$ Division of Cardiothoracic Surgery, Washington University School of Medicine, St. Louis, MO
}

\begin{abstract}
Background-Although several studies have examined factors affecting survival after orthotopic heart transplantation (OHT), few have evaluated the impact of reoperative sternotomy. We undertook this study to examine the incidence and impact of repeat sternotomies on OHT outcomes.
\end{abstract}

\begin{abstract}
Methods-We conducted a retrospective review of all adult OHT from two institutions. Primary stratification was by the number of prior sternotomies. The primary outcome was survival. Secondary outcomes included blood product utilization and commonly encountered postoperative complications. Multivariable Cox proportional hazards regression models examined mortality while linear regression models examined blood utilization.
\end{abstract}

Results-From 01/1995-10/2011, 631 OHT were performed. Of these, 25 (4.0\%) were redo OHT and 182 (28.8\%) were bridged to transplant with a ventricular assist device. 356 (56.4\%) had undergone at least 1 prior sternotomy. On unadjusted analysis, reoperative sternotomy was associated with decreased 90 -day $(98.5 \%$ vs. $90.2 \%$, p $<0.001)$, 1 -year $(93.1 \%$ vs. $79.6 \%$, $\mathrm{p}<0.001)$, and 5 -year ( $80.4 \%$ vs. $70.1 \%, \mathrm{p}=0.002)$ survival. This difference persisted on multivariable analysis at 90-days (HR: 2.99, $\mathrm{p}=0.01$ ), 1-year (HR: 2.98, $\mathrm{p}=0.002$ ), and 5-years (HR: 1.62, $\mathrm{p}=0.049$ ). The impact of an increasing number of prior sternotomies was negligible. On multivariable analysis, an increasing number of prior sternotomies was associated with increased intraoperative blood product utilization. Increasing blood utilization was associated with decreased 90-day, 1-year, and 5-year survival.

Conclusions-Reoperative sternotomy is associated with increased mortality and blood utilization after OHT. Patients with more than 1 prior sternotomy do no experience additional

(C) 2012 The Society of Thoracic Surgeons. Published by Elsevier Inc. All rights reserved.

Correspondence: Scott C. Silvestry, MD, Associate Professor of Surgery, Washington University School of Medicine, Department of Surgery, Division of Cardiothoracic Surgery, CB 8234, 660 S. Euclid Ave. St. Louis, MO 63110, 314-362-6182 (phone), 314-747-4216 (fax), silvestrys@wudosis.wustl.edu.

Presentation: The contents of this manuscript were presented at the $32^{\text {nd }}$ Annual Meeting of the ISHLT.

Publisher's Disclaimer: This is a PDF file of an unedited manuscript that has been accepted for publication. As a service to our customers we are providing this early version of the manuscript. The manuscript will undergo copyediting, typesetting, and review of the resulting proof before it is published in its final citable form. Please note that during the production process errors may be discovered which could affect the content, and all legal disclaimers that apply to the journal pertain. 
increased mortality. Carefully selected patients with multiple prior sternotomies have decreased but acceptable outcomes.

\section{Keywords}

Transplantation; Heart; Outcomes; Surgery/incisions/exposure/techniques

\section{INTRODUCTION}

Orthotopic heart transplantation(OHT) is the gold-standard for the treatment of end-stage heart failure.[1] As outcomes have improved, the indications for OHT, and thus the number of potential recipients, have continued to increase.[2,3] Unfortunately, because of the relatively stagnant donor pool, the number of OHT performed annually has not changed in almost two decades.[1,3] Thus, given the relative shortage of donor hearts available for OHT, appropriate recipient risk stratification is paramount to ensure optimal allocation of this scarce resource.[3]

As the waitlist grows and mechanical circulatory support technology improves, an increasing number of patients are being bridged to transplantation(BTT) with a ventricular assist device(VAD).[4] Moreover, an increasing number of patients with heart failure are undergoing non-transplant cardiac surgery to optimize cardiac function before progressing to heart failure requiring VAD or OHT.[3,5,6] Thus an increasing number of potential recipients are presenting for OHT having undergone one or more prior sternotomy.[3,6] Therefore, it is incumbent on surgeons to understand the impact of reoperative sternotomy on outcomes after OHT. Although reoperative sternotomy is a known risk factor for morbidity and mortality after coronary bypass surgery, its impact on OHT outcomes is unclear.[2,3,6-13] Moreover, most previous studies represent single center experiences of limited sample size. Additionally, most current OHT risk scores do not incorporate reoperative sternotomy because these data are not adequately captured by existing registries. $[14,15]$ Therefore, we undertook this multi-institutional study to characterize the incidence and impact of reoperative sternotomy on outcomes after OHT.

\section{MATERIAL AND METHODS}

\section{Study Design}

We conducted a retrospective review of the cardiac surgery databases at both the Johns Hopkins and the Barnes-Jewish Hospitals. Our study included all adult( $\geq 18$ years) OHT from 1995-2011. Patients undergoing combined heart-lung transplantation were excluded. Each hospital's institutional review board approved this study.

We examined pertinent variables in our data set, including recipient demographics and comorbidities; hemodynamics, measures of acuity, and need for support; donor demographics and co-morbidities; and transplant variables.

Patient records were reviewed for the number of previous sternotomies prior to OHT. Primary stratification was according to the number of prior sternotomies: 0,1 , or $\geq 2$. Subgroup analysis focused on BTT patients. Secondary stratification was by intraoperative blood product utilization. The primary outcomes were 90-day, 1-year, and 5-year survival. Secondary outcomes included common postoperative complications, blood product utilization, and predictors of blood product use. 


\section{Statistical Analysis}

We compared baseline characteristics stratified by the number of prior sternotomies using analysis of variance(ANOVA) for continuous variables and the Chi-square or Fisher's exact test for categorical variables as appropriate. For associations found to be significant according to preliminary analysis, post hoc pair-wise comparisons were performed using the Tukey-Kramer method for continuous variables and by univariate logistic regression for categorical variables.

Survival was calculated by the Kaplan-Meier method and survival comparisons were performed using the log-rank test. To further analyze mortality, multivariable Cox proportional hazards regression models were constructed. Blood product utilization was analyzed with multivariable linear regression. To construct the multivariable models, all independent covariates were tested in univariate fashion. Variables associated with the outcome measure on exploratory analysis $(\mathrm{p}<0.20)$, those with previous literature support, and those with biological plausibility were incorporated in a forward and backward stepwise fashion into the multivariable model. The likelihood ratio test and Akaike's information criterion were utilized in a nested model approach to identify which model had the greatest explanatory power. This method favors a more parsimonious model.

For all analyses, values of $\mathrm{p}<0.05$ (2-tailed) were considered statistically significant. Mean values are displayed with standard deviations and median values are displayed with their interquartile ranges(IQR). Hazard ratios(HR) and linear regression coefficients are presented with their 95\% confidence intervals(CI). Statistical analysis was performed using Stata 12.0(StataCorp, College Station, TX).

\section{RESULTS}

\section{Cohort Statistics}

From 1995-2011, 631 patients underwent OHT. The mean age was 50( \pm 12$)$ years and $425(78.0 \%)$ of the patients were male. The most common pre-OHT diagnosis was idiopathic dilated cardiomyopathy $(\mathrm{n}=252,39.9 \%)$ followed by ischemic cardiomyopathy $(\mathrm{n}=222$, $35.2 \%)$. 14(2.2\%) patients had congenital heart disease.

In this cohort, 25(4.0\%) patients were redo-OHT and 356(56.4\%) had undergone at least 1 prior sternotomy(number of prior sternotomies - 0: 275(43.6\%); 1: 295(46.8\%); 2 : $47(7.5 \%) ; 3: 10(1.6 \%) ; ㄴ 44: 4(0.6 \%) .182(28.8 \%)$ patients were bridged to OHT with a LVAD, 61(9.7\%) with a continuous flow device and 121(19.2\%) with either a pulsatile or temporary support device.

In the study period, 223(37.4\%) patients died with a median follow-up of 5.2 [IQR: 1.6-9.1] years. Overall 90-day, 1-year, and 5-year survival were $90.1 \%, 85.5 \%$, and $74.6 \%$, respectively.

\section{Baseline Characteristics}

When stratified by the number of prior sternotomies $(0,1$, or $\geq 2)$, most baseline characteristics were well-matched between the groups(Table 1). Patients with no prior sternotomies were more likely to be female. As expected, patients with multiple prior sternotomies were more likely to have been bridged to OHT with a VAD, more likely to have undergone a previous OHT, and more likely to have congenital heart disease. Additionally, as the number of prior sternotomies increased, patients required increasing cardiopulmonary bypass(CPB) durations. Although several other variables were statistically different, most of the absolute differences were small and unlikely clinically relevant. 


\section{Sternotomy Outcomes}

On unadjusted analysis, reoperative sternotomy was associated with a decreased 90day $(98.5 \%$ vs. $90.2 \%, \mathrm{p}<0.001), 1-y e a r(93.1 \%$ vs. $79.6 \%$, p $<0.001)$, and $5-y e a r(80.4 \%$ vs. $70.1 \%, p=0.002$; Figure 1a) survival. Most of this increased mortality appears to be the result of early, perioperative mortality. Although those who survive to 90-days still have slightly lower 1-year survival $(\mathrm{p}=0.04)$, they have similar survival at 5 -years $(\mathrm{p}=0.4$; Figure $1 b)$. When stratified by the number of prior sternotomies, patients with 1 or more prior sternotomies had a decreased 1-year survival compared to those without prior sternotomy $(0$ : $93.1 \%$ vs. $1: 80.4 \%$ vs. $\geq 2: 75.7 \%$, p $<0.001$; Figure 2). Although patients with $\geq 2$ prior sternotomies had decreased 1-year survival compared to those with no prior sternotomies $(\mathrm{p}<0.001)$, patients with 2 prior sternotomies had similar 1-year survival as those with 1 prior sternotomy( $\mathrm{p}=0.6)$. These survival differences were still significant if patients undergoing redo-OHT and patients with congenital heart disease were excluded( $\mathrm{p}<0.01$ at all 3 time points).

On unadjusted analysis, BTT patients had decreased 90 -day( $92.9 \%$ vs. $83.2 \%$, $\mathrm{p}=0.005), 1$ year $(88.1 \%$ vs. $79.0 \%, \mathrm{p}=0.02)$, and $5-\operatorname{year}(77.2 \%$ vs. $68.2 \%, \mathrm{p}=0.04)$ survival compared to those not requiring VAD support. However, after adjusting for recipient, donor, and transplant variables, BTT was not associated with an increased hazard of mortality at 90days(HR: 1.11 [0.53-2.33], p=0.8), 1-year(HR: 0.84 [0.44-1.61], p=0.6), or 5-years(HR: $1.01[0.60-1.71], \mathrm{p}=0.9)$. Moreover, when all BTT patients were compared to other patients with 1 prior sternotomy, there was no difference in 90 -day $(\mathrm{p}=0.3), 1$-year $(\mathrm{p}=0.3)$, or 5year $(\mathrm{p}=0.8)$ survival. Finally, when restricted to BTT patients bridged with a Heartmate II(Thoratec Corporation, Pleasanton, CA) device, there was no difference in mortality at 90days $(\mathrm{p}=0.8), 1$-year( $\mathrm{p}=0.9)$, or 5 -years $(\mathrm{p}=0.7)$ compared to patients not bridged to OHT. These findings also persisted on adjusted analysis.

Excluding patients bridged to OHT with a VAD, the need for reoperative sternotomy was still associated with decreased 90 -day( $96.2 \%$ vs. $87.7 \%$, p=0.01), 1-year(93.1\% vs. $80.2 \%$, $\mathrm{p}<0.001)$, and 5-year( $80.4 \%$ vs. $71.9 \%, \mathrm{p}=0.02)$ survival. Additionally, although the numbers are small, patients undergoing redo-OHT $(\mathrm{n}=25)$ had similar 1-year survival as patients undergoing primary $\mathrm{OHT}(85.7 \%$ vs. $80.0 \%, \mathrm{p}=0.3)$.

On adjusted analysis, reoperative sternotomy was associated with increased 90-day(HR: 2.99 [1.28-6.94], $\mathrm{p}=0.01$ ), 1-year(HR: 2.98 [1.51-5.86], $\mathrm{p}=0.002$; Table 2), and 5-year(HR: 1.62 [1.01-2.62], $\mathrm{p}=0.049)$ mortality. In these models, increasing creatinine, bilirubin, donor age, and ischemic time were all associated with increased mortality. No factors were protective. When stratified by the number of prior sternotomies, 1 prior sternotomy was associated with increased mortality compared to no prior sternotomies(Table 3). An increasing number of prior sternotomies was not associated with additional mortality.

\section{Complications}

An increasing number of prior sternotomies at the time of OHT was associated with a longer total and ICU length of stay, an increased need for cardiac reoperation, more perioperative infections and episodes of rejection, a higher incidence of stroke, a greater need for renal replacement therapy, and an increased utilization of blood products(Table 4).

\section{Blood Product Utilization}

The number of prior sternotomies correlated with the intraoperative utilization of blood products(Coefficient: 6.18 units/sternotomy, $\mathrm{p}<0.001$ ). On adjusted analysis, this correlation persisted(Coefficient: 3.52 units/sternotomy, $\mathrm{p}<0.001$ ). 
Blood product utilization was divided into equal quartiles. When stratified by intraoperative blood utilization, increased blood utilization was associated with decreased survival at 90days $(\mathrm{p}=0.001), 1$-year $(\mathrm{p}=0.004)$, and 5 -years $(\mathrm{p}=0.01$; Figure 3$)$. On adjusted analysis, each unit of intraoperative blood product was associated with an increased risk of 90-day(HR: 1.03 [1.01-1.05], $\mathrm{p}=0.001), 1-y e a r(H R: 1.03$ [1.02-1.05], $\mathrm{p}<0.001)$, and 5-year(HR: 1.02 [1.01-1.03], $\mathrm{p}=0.01$ ) mortality.

\section{COMMENT}

In this multi-institutional study, we found that reoperative sternotomy is associated with decreased short and long-term survival after OHT. Additionally, reoperative sternotomy is associated with increased length of stay, perioperative morbidity, and blood product utilization. An increasing number of prior sternotomies was not associated with additional mortality. On adjusted analysis, BTT patients had similar mortality as patients not requiring VAD support, particularly in the modern era of continuous flow devices. Finally, an increasing number of prior sternotomies was associated with increased perioperative blood product utilization which was independently associated with decreased survival.

\section{Reoperative Sternotomy}

Unfortunately, the number of patients awaiting an OHT exceeds the number of transplants performed. Therefore, since many potential OHT recipients will die waiting for an available organ, or, alternatively, receive a VAD, appropriate and accurate risk stratification is essential to optimize the outcomes associated with the use of donor hearts, a scarce societal resources.[3] To this end, several researchers have utilized registry data to create and validate OHT recipient risk scores.[14,15] Although these useful scores have the strength of being based on a large number of OHT, they are limited to the variables collected in these registries. While the United Network for Organ Sharing database collects information on prior cardiac surgery, it does not indicate the number of prior sternotomies. Moreover, this field contains a significant amount of missing data. Therefore, in creating these risk scores, this variable was not considered for inclusion.

Despite the absence of reoperative sternotomy from many risk scores, intuitively, redo sternotomy should be associated with an increased risk of mortality. Reoperative surgery can be associated with dense adhesions and distorted anatomy.[9] Thus, redo sternotomies are associated with increased risk of injury to the heart and great vessels.[3] Moreover, sternal reentry may require alternative methods of cannulation, with their associated risks. All of these potential hazards may result in iatrogenic injury, catastrophic hemorrhage, increased blood product utilization, and prolonged CPB time. Furthermore, reoperative sternotomy is a known risk factor for morbidity and mortality after other cardiac surgery operations. Several recent series confirm that coronary artery bypass grafting requiring a redo sternotomy continues to be associated with increased perioperative mortality.[7,8]

However, the current literature on the impact of reoperative sternotomy on outcomes after OHT is mixed. In 1989, Lammermeier et al.[13] reported on 182 OHT patients, 72 of whom had a prior sternotomy. Although they found reoperative sternotomy was associated with an increased risk of reoperation for bleeding, the patients had similar 1 and 3-year survival.[13] Since that time, several studies have found patients requiring a reoperative sternotomy at the time of OHT to have decreased short and long-term survival[2,3,12]; however, other studies, many of limited sample size, have found no survival difference.[6,9-11]

In our study, reoperative sternotomy was significantly associated with decreased survival. Interestingly, when stratified by the number of prior sternotomies, an unadjusted analysis of increasing number of sternotomies appeared to be associated with increased mortality. 
However, on post hoc and multivariable analysis, $\geq 2$ prior sternotomies was not associated with a significantly lower survival compared to 1 prior sternotomy. However, despite this negative finding, there was a trend toward increased morbidity and mortality. The relatively small number of patients with $\geq 2$ prior sternotomies may have led to a type 2 error. In fact, given the current differences in 1-year survival, we would need 350 patients each with 1 prior and $\geq 2$ prior sternotomies to have $80 \%$ power to detect a statistically significant difference between the two cohorts. Further investigation with a larger sample size is necessary to determine the incremental impact of additional reoperative sternotomies.

Previous studies have also found reoperative sternotomy to be associated with significantly increased morbidity after OHT, including an. increased length of stay; $[6,9,12]$ longer operations, $[2,6,9,12]$ cold ischemic time, [6] and CPB time[9,10,12]; increased blood product utilization, $[3,6,9,10]$ risk of reoperation for bleeding, $[2,3,6,9,13]$, and incidence of postoperative infection.[2] In addition to these complications, our study found OHT after prior sternotomy to be associated with an increased risk of stroke. Moreover, while our study lacked the size to statistically evaluate the additive risk for each additional sternotomy, there an increasing incidence of each complication with each additional reoperation.

\section{Bridge to Transplantation}

As mechanical circulatory support technology improves, an increasing number of patients are being bridged to OHT.[4] Although early reports with pulsatile devices suggested that BTT patients had increased mortality, more recent reports suggest this difference is diminishing.[16,17] In our study, on unadjusted analysis, BTT patients had decreased short and long-term survival. However, after adjusting for recipient, donor, and transplant factors, BTT patients had similar mortality as patients not requiring VAD support. Moreover, when compared to non-bridged patients with 1 prior sternotomy, there was no survival difference. These findings suggest that although BTT patients may have more co-morbidities and may be of higher acuity when they receive their OHT, the impact of the VAD support itself does not influence survival. In fact, much of the survival difference may be due to the risks of the reoperative sternotomy itself.

Furthermore, patients bridged to transplantation with a Heartmate II device had similar short and long-term survival as patients not requiring VAD support. These findings confirm the trends in the literature that suggest that the increased mortality associated with BTT continues to abate in the modern era.

\section{Blood Product Utilization}

Not unexpectedly, this study also found the number of prior sternotomies to be associated with an increased utilization of blood products. When stratified by quartiles, increasing blood product utilization was independently associated with increased short and long-term mortality. To our knowledge, we are the first to report this finding in OHT patients.

Although blood and blood product transfusion can be lifesaving, there is a growing consensus in the literature that a restrictive approach to blood transfusions is associated with equivalent or improved outcomes.[18,19] Our findings, and those of others, suggest the risk of blood product transfusion may be additive, with each unit causing an incremental increase in risk.[20] In transplantation, this risk may be compounded by the immunomodulatory and sensitizing impact of each transfusion. While it may be difficult to significantly alter the quantity of blood product transfusions in patients undergoing OHT, particularly those undergoing a redo sternotomy, it is important to realize that increased blood product requirement may affect patient survival. 


\section{Limitations}

Our study has several limitations. First, although we combined two academic, tertiary referral centers to increase our sample size, several of our study subgroups are comprised of a limited number of patients. Thus our study is susceptible to a type II error. In particular, although our findings suggest that an increasing number of prior sternotomies is associated with an incremental increase in mortality, we were unable to demonstrate statistical significance for this trend. Further research with a larger sample size is needed to better define the risk of multiple prior sternotomies. Second, although many technical factors including sternal re-entry technique, cannulation strategies, and blood conservation techniques may affect our findings, we were unable to assess them in this retrospective review. Investigation of the impact of technical factors on reoperative sternotomy for OHT is warranted. Third, patients with ischemic CM are more likely to have a prior sternotomy and are known to have poorer OHT outcomes than patients with dilated CM. The inability to separate the interaction between heart failure etiology and number of prior sternotomies is a limitation.

\section{Conclusions}

In conclusion, reoperative sternotomy is associated with increased morbidity and mortality after OHT. Moreover, patients undergoing reoperative sternotomy require increased perioperative blood product transfusions which are independently associated with decreased survival. Therefore, reoperative sternotomy should be considered when evaluating the risk profile of potential recipients. Nevertheless, carefully selected patients with multiple prior sternotomies can have acceptable outcomes and should not be excluded from OHT.

\section{Acknowledgments}

The authors would like to thank Ms. Diane Alejo, Ms. Tina Burmeister, Mr. Joe Dinatale, Ms. Barbara Fleischman, Mr. Mike Sickinger, and Ms. Jo Tyler for their support with data collection.

This research was supported in part by grant T32 2T32DK007713-12 from the National Institutes of Health. Dr. George is the Hugh R. Sharp Cardiac Surgery Research Fellow. Dr. Beaty is the Irene Piccinini Investigator in Cardiac Surgery.

\section{ABBREVIATIONS AND ACRONYMS}

$\begin{array}{ll}\text { ANOVA } & \text { Analysis of variance } \\ \text { BMI } & \text { Body mass index } \\ \text { BTT } & \text { Bridge to transplantation } \\ \text { CI } & \text { Confidence intervals } \\ \text { CPB } & \text { Cardiopulmonary bypass } \\ \text { HR } & \text { Hazard ratio } \\ \text { IABP } & \text { Intra-aortic balloon pump } \\ \text { ICU } & \text { Intensive care unit } \\ \text { IQR } & \text { Interquartile ranges } \\ \text { OHT } & \text { Orthotopic heart transplantation } \\ \text { PA } & \text { Pulmonary artery } \\ \text { VAD } & \text { Ventricular assist device }\end{array}$




\section{References}

1. Stehlik J, Edwards LB, Kucheryavaya AY, et al. The Registry of the International Society for Heart and Lung Transplantation: Twenty-eighth Adult Heart Transplant Report--2011. J Heart Lung Transplant. 2011; 30(10):1078-94. [PubMed: 21962016]

2. Uthoff K, Wahlers T, Cremer J, Borst HG. Previous open heart operation: a contribution to impaired outcome after cardiac transplantation? Ann Thorac Surg. 1997; 63(1):117-23. [PubMed: 8993252]

3. Vijayanagar R, Chan G, Weinstein S. Effect of previous nontransplant cardiac operations on the outcome of heart transplantation. J Thorac Cardiovasc Surg. 1994; 108(6):1149-50. [PubMed: 7848482]

4. Kirklin JK, Naftel DC, Kormos RL, et al. The Fourth INTERMACS Annual Report: 4,000 implants and counting. J Heart Lung Transplant. 2012; 31(2):117-26. [PubMed: 22305376]

5. George TJ, Arnaoutakis GJ, Shah AS. Surgical treatment of advanced heart failure: alternatives to heart transplantation and mechanical circulatory assist devices. Prog Cardiovasc Dis. 2011; 54(2): 115-31. [PubMed: 21875511]

6. Kokkinos C, Athanasiou T, Rao C, et al. Does re-operation have an effect on outcome following heart transplantation? Heart Lung Circ. 2007; 16(2):93-102. [PubMed: 17314069]

7. Yap CH, Sposato L, Akowuah E, et al. Contemporary results show repeat coronary artery bypass grafting remains a risk factor for operative mortality. Ann Thorac Surg. 2009; 87(5):1386-91. [PubMed: 19379870]

8. Sabik JF 3rd, Blackstone EH, Houghtaling PL, Walts PA, Lytle BW. Is reoperation still a risk factor in coronary artery bypass surgery? Ann Thorac Surg. 2005; 80(5):1719-27. [PubMed: 16242445]

9. Aziz T, Burgess M, Rahman A, et al. Early and long-term results of heart transplantation after previous cardiac surgery. Eur J Cardiothorac Surg. 2000; 17(4):349-54. [PubMed: 10773554]

10. Handa NMS, O'Fallon WM, Daly RC, McGregor CGA. The Influence of Prior Median Sternotomy on Outcome of Heart Transplantation. Asian Cardiovasc Thorac Ann. 1998; 6:17-22.

11. Carrel T, Neth J, Mohacsi P, Gallino A, Turina MI. Perioperative risk and long-term results of heart transplantation after previous cardiac operations. Ann Thorac Surg. 1997; 63(4):1133-7. [PubMed: 9124919]

12. Ott GY, Norman DJ, Hosenpud JD, et al. Heart transplantation in patients with previous cardiac operations. Excellent clinical results. J Thorac Cardiovasc Surg. 1994; 107(1):203-9. [PubMed: 8283886]

13. Lammermeier DE, Nakatani T, Sweeney MS, et al. Effect of prior cardiac surgery on survival after heart transplantation. Ann Thorac Surg. 1989; 48(2):168-72. [PubMed: 2669645]

14. Weiss ES, Allen JG, Arnaoutakis GJ, et al. Creation of a quantitative recipient risk index for mortality prediction after cardiac transplantation (IMPACT). Ann Thorac Surg. 2011; 92(3):91421. discussion 21-2. [PubMed: 21871277]

15. Hong KN, Iribarne A, Worku B, et al. Who is the high-risk recipient? Predicting mortality after heart transplant using pretransplant donor and recipient risk factors. Ann Thorac Surg. 2011; 92(2):520-7. discussion 7. [PubMed: 21683337]

16. Patlolla V, Patten RD, Denofrio D, Konstam MA, Krishnamani R. The effect of ventricular assist devices on post-transplant mortality an analysis of the United network for organ sharing thoracic registry. J Am Coll Cardiol. 2009; 53(3):264-71. [PubMed: 19147043]

17. Pal JD, Piacentino V, Cuevas AD, et al. Impact of left ventricular assist device bridging on posttransplant outcomes. Ann Thorac Surg. 2009; 88(5):1457-61. discussion 61. [PubMed: 19853092]

18. Hajjar LA, Vincent JL, Galas FR, et al. Transfusion requirements after cardiac surgery: the TRACS randomized controlled trial. JAMA. 2010; 304(14):1559-67. [PubMed: 20940381]

19. Hebert PC, Wells G, Blajchman MA, et al. A multicenter, randomized, controlled clinical trial of transfusion requirements in critical care. Transfusion Requirements in Critical Care Investigators, Canadian Critical Care Trials Group. N Engl J Med. 1999; 340(6):409-17. [PubMed: 9971864]

20. Whitson BA, Huddleston SJ, Savik K, Shumway SJ. Risk of adverse outcomes associated with blood transfusion after cardiac surgery depends on the amount of transfusion. J Surg Res. 2010; 158(1):20-7. [PubMed: 19181341] 


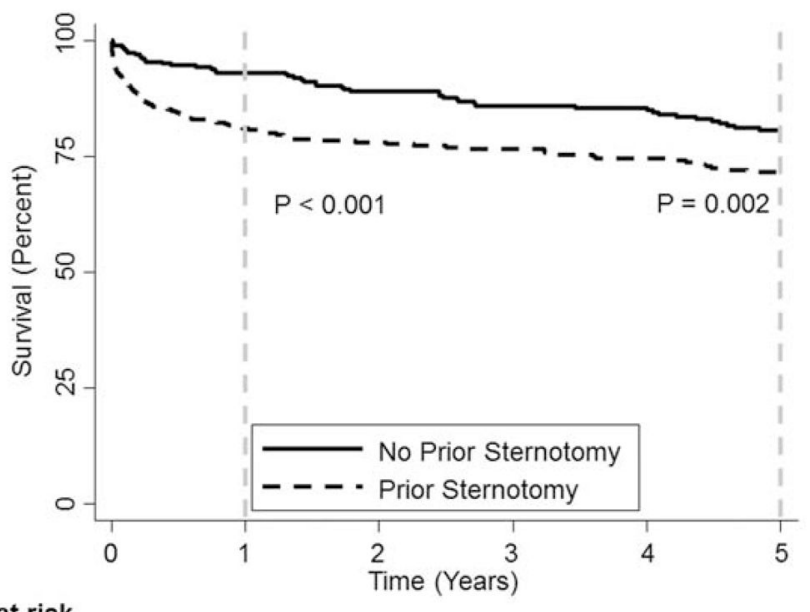

Number at risk

$\begin{array}{rlllll}\text { No Prior Sternotomy } 261 & 234 & 212 & 194 & 182 & 150 \\ \text { Prior Sternotomy } 329 & 252 & 220 & 202 & 183 & 159\end{array}$

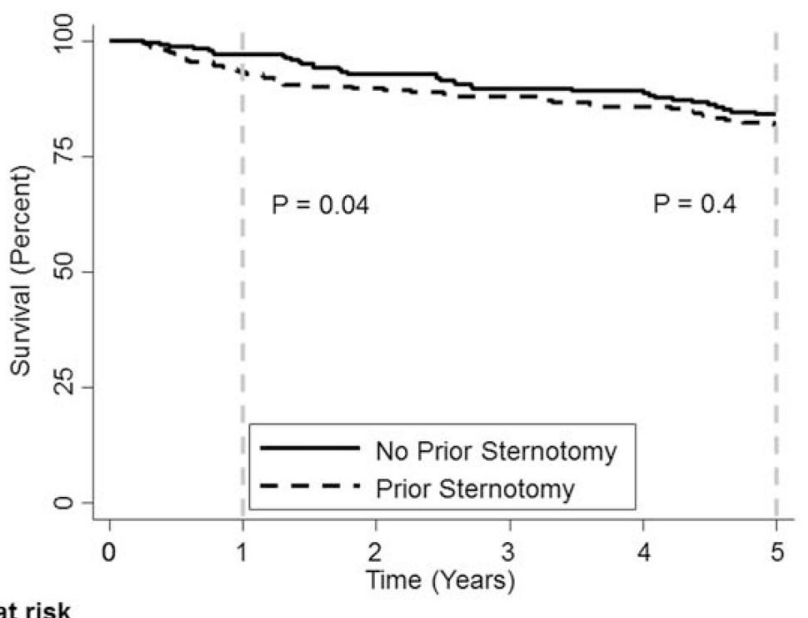

Number at risk

No Prior Sternotomy

Prior Sternotomy

$\begin{array}{lllll}234 & 212 & 194 & 182 & 150 \\ 252 & 220 & 202 & 183 & 159\end{array}$

Figure 1.

(A) 5-year Kaplan-Meier survival stratified by sternotomy prior to OHT. (B) 5-year KaplanMeier survival conditional on 90-day survival stratified by sternotomy prior to OHT. Solid lines depict recipients without a prior sternotomy. Dashed lines depict patients with a prior sternotomy. P-values determined by the log-rank test. 


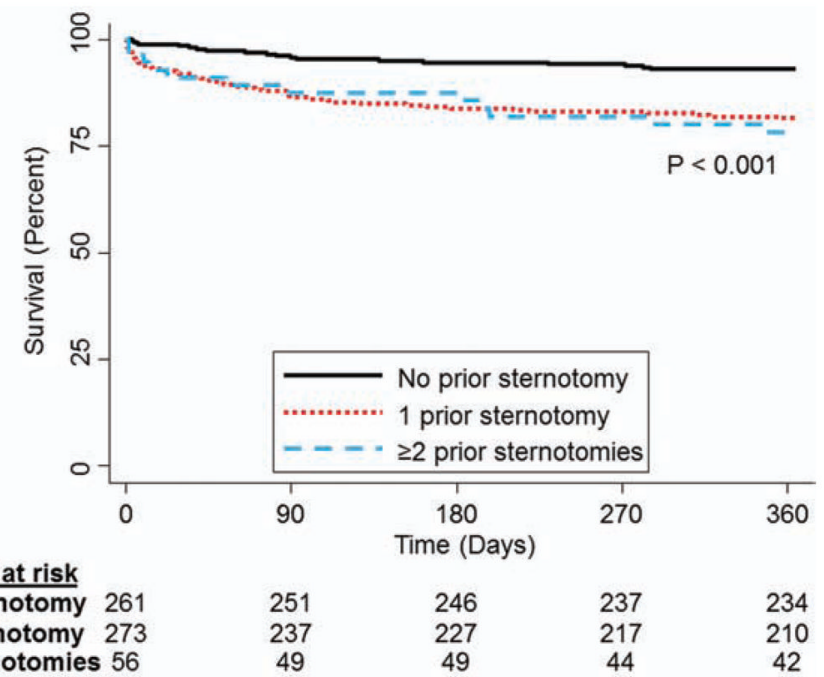

Figure 2.

1-Year Kaplan-Meier survival stratified by number of sternotomies prior to OHT. Solid black line depicts recipients without a prior sternotomy, dashed red line 1 prior sternotomy, dashed-dotted blue line 2 prior sternotomies, and fine dotted green line $\geq 3$ prior sternotomies. P-values determined by the log-rank test. 


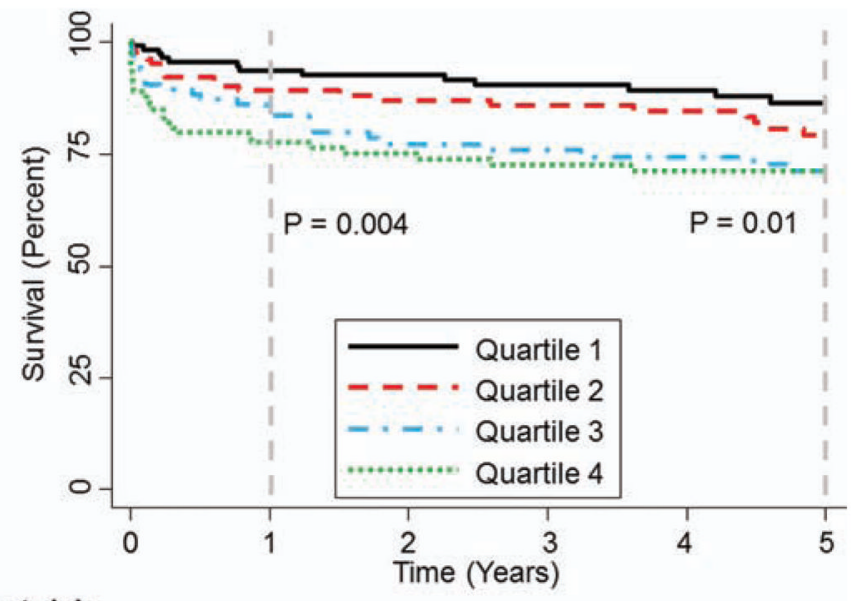

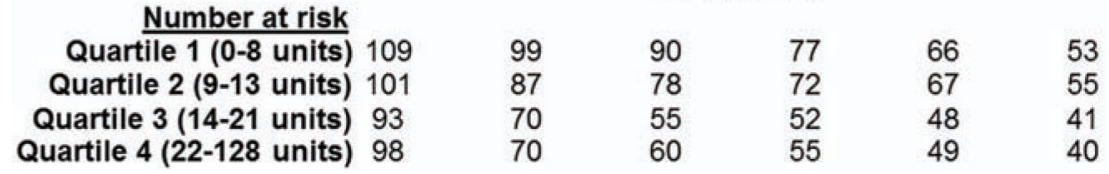

Figure 3.

5-Year Kaplan-Meier survival stratified by quantity of intraoperative blood received. Solid black line depicts recipients in the $1^{\text {st }}$ quartile, dashed red line $2^{\text {nd }}$ quartile, dashed-dotted blue line $3^{\text {rd }}$ quartile, and fine dotted green line $4^{\text {th }}$ quartile. P-values determined by the logrank test. 
Table 1

Baseline Characteristics Stratified by the Number of Prior Sternotomies

\begin{tabular}{|c|c|c|c|c|}
\hline Variable & $\begin{array}{c}0 \text { Prior Sternotomies } \\
(\mathbf{n = 2 7 5})\end{array}$ & $\begin{array}{c}1 \text { Prior Sternotomy } \\
(\mathrm{n}=295)\end{array}$ & $\underset{(n=61)}{\geq 2 \text { Prior Sternotomies }}$ & P-Value* \\
\hline \multicolumn{5}{|c|}{ Recipient Demographics and Co-Morbidities } \\
\hline Age, years & $49( \pm 12)$ & $50( \pm 13)$ & $52( \pm 13)$ & 0.3 \\
\hline Male gender $(\%)$ & $163 / 274(59.5 \%)$ & $217 / 295(73.6 \%)$ & $45 / 61(73.8 \%)$ & $0.001^{a, b}$ \\
\hline White ethnicity (\%) & $217 / 274(79.2 \%)$ & $230 / 293(78.5 \%)$ & $52 / 61(85.3 \%)$ & 0.5 \\
\hline Black ethnicity (\%) & $51 / 274(18.6 \%)$ & $55 / 293(18.8 \%)$ & $6 / 61(9.8 \%)$ & 0.2 \\
\hline Other ethnicity (\%) & $6 / 274(2.2 \%)$ & $8 / 293(2.7 \%)$ & $3 / 61(4.9 \%)$ & 0.5 \\
\hline Creatinine, $\mathrm{mg} / \mathrm{dL}$ & $1.2( \pm 0.4)$ & $1.3( \pm 0.6)$ & $1.5( \pm 0.9)$ & $0.002^{b, c}$ \\
\hline Total bilirubin, $\mathrm{mg} / \mathrm{dL}$ & $0.8[0.5-1.2]$ & $0.7[0.5-1.1]$ & $0.65[0.5-1.0]$ & 0.5 \\
\hline Diabetes (\%) & $54 / 267(20.2 \%)$ & $53 / 272(19.5 \%)$ & $10 / 59(17.0 \%)$ & 0.8 \\
\hline BMI, $\mathrm{kg} / \mathrm{m}^{2}$ & $26( \pm 6)$ & $27( \pm 6)$ & $27( \pm 5)$ & 0.1 \\
\hline Idiopathic etiology (\%) & $84 / 275(30.6 \%)$ & $108 / 295(36.6 \%)$ & $30 / 61(49.2 \%)$ & $0.02^{b}$ \\
\hline Ischemic etiology (\%) & $129 / 275(46.9 \%)$ & $108 / 295(36.6 \%)$ & $15 / 61(24.6 \%)$ & $0.002^{a, b}$ \\
\hline Congenital etiology (\%) & $6 / 275(2.2 \%)$ & $3 / 295(1.0 \%)$ & $5 / 61(8.2 \%)$ & $0.002^{b, c}$ \\
\hline Other etiology (\%) & $56 / 275(20.4 \%)$ & $76 / 295(25.8 \%)$ & $11 / 61(18.0 \%)$ & 0.2 \\
\hline \multicolumn{5}{|c|}{ Hemodynamics, Need for Support, and Measures of Acuity } \\
\hline Cardiac output, $\mathrm{L} / \mathrm{min}$ & $4.3( \pm 1.4)$ & $4.5( \pm 1.4)$ & $4.4( \pm 1.3)$ & 0.1 \\
\hline Mean PA pressure, $\mathrm{mmHg}$ & $28( \pm 9)$ & $29( \pm 11)$ & $28( \pm 10)$ & 0.8 \\
\hline PCWP, mmHg & $19( \pm 8)$ & $19( \pm 9)$ & $18( \pm 8)$ & 0.9 \\
\hline $\mathrm{TPG}, \mathrm{mmHg}$ & $9( \pm 6)$ & $9( \pm 5)$ & $10( \pm 9)$ & 0.9 \\
\hline Hospitalized (\%) & $80 / 261(30.7 \%)$ & $114 / 277(41.2 \%)$ & $16 / 58(27.6 \%)$ & $0.02^{a}$ \\
\hline $\mathrm{ICU}(\%)$ & $50 / 261(19.2 \%)$ & $59 / 277(21.3 \%)$ & $8 / 58(13.8 \%)$ & 0.4 \\
\hline Inotropic support (\%) & $100 / 261(38.3 \%)$ & $86 / 277(31.1 \%)$ & $16 / 58(27.6 \%)$ & 0.1 \\
\hline IABP support (\%) & $7 / 275(2.6 \%)$ & $25 / 295(8.5 \%)$ & $1 / 61$ & $0.003^{a}$ \\
\hline No VAD support (\%) & $275 / 275(100 \%)$ & $130 / 295(44.1 \%)$ & $44 / 61(72.1 \%)$ & $<0.001^{a, b, c}$ \\
\hline Pulsatile VAD support (\%) & $0 / 275(0 \%)$ & $115 / 295(39.0 \%)$ & $6 / 61(9.8 \%)$ & $<0.001^{a, b, c}$ \\
\hline Continuous Flow VAD support (\%) & $0 / 275(0 \%)$ & $50 / 295(17.0 \%)$ & $11 / 61(18.0 \%)$ & $<0.001^{a, b}$ \\
\hline \multicolumn{5}{|l|}{ Donor and Transplant Variables } \\
\hline Redo-OHT (\%) & $0 / 275(0 \%)$ & $22 / 295(7.5 \%)$ & $3 / 61(4.9 \%)$ & $<0.001^{a, b}$ \\
\hline Age, years & $30( \pm 12)$ & $30( \pm 12)$ & $32( \pm 12)$ & 0.5 \\
\hline Male gender $(\%)$ & $145 / 244(59.4 \%)$ & $172 / 232(74.1 \%)$ & $34 / 51(66.7 \%)$ & $0.003^{a, b}$ \\
\hline Same gender matching (\%) & $154 / 275(56.0 \%)$ & $164 / 295(55.6 \%)$ & $38 / 61(62.3 \%)$ & 0.6 \\
\hline Ischemic time, hours & $2.8( \pm 0.9)$ & $3.0( \pm 1.0)$ & $3.1( \pm 1.0)$ & 0.1 \\
\hline Cardiopulmonary bypass time, min & $156( \pm 50)$ & $191( \pm 68)$ & $193( \pm 58)$ & $<0.001^{a, b}$ \\
\hline Aortic cross clamp time, min & $123( \pm 66)$ & $124( \pm 64)$ & $137( \pm 73)$ & 0.3 \\
\hline
\end{tabular}


${ }^{b}$ Cohort 1 significantly different than cohort 3

${ }^{c}$ Cohort 2 significantly different than cohort 3 
Table 2

Multivariable Cox Proportional Hazards Regression Model of 1-Year Mortality

\begin{tabular}{|lccc|}
\hline Variable & HR & 95\% Confidence Interval & P-Value \\
\hline Any prior sternotomy & 2.98 & $1.51-5.86$ & 0.002 \\
Recipient age (per year) & 1.00 & $0.98-1.03$ & 0.9 \\
Recipient creatinine (per mg/dL) & 1.80 & $1.33-2.44$ & $<0.001$ \\
Recipient bilirubin (per mg/dL) & 1.15 & $1.04-1.27$ & 0.005 \\
Congenital heart disease & 0.40 & $0.05-3.03$ & 0.4 \\
No VAD & & 1 (Reference) \\
Older generation pulsatile VAD & 0.98 & $0.50-1.95$ & -- \\
Newer generation continuous flow VAD & 0.54 & $0.18-1.61$ & 0.9 \\
Donor age (per year) & 1.03 & $1.01-1.05$ & 0.3 \\
Redo OHT & 0.48 & $0.13-1.76$ & 0.01 \\
Ischemic time (per hour) & 1.35 & $1.03-1.78$ & 0.3 \\
\hline
\end{tabular}




\section{Table 3}

Multivariable Hazard Ratios of Mortality Relative to No Prior Sternotomy

\begin{tabular}{|ccccc|}
\hline \multirow{2}{*}{ Time } & \multicolumn{2}{c}{$\mathbf{1}$ Prior Sternotomy } & \multicolumn{2}{c|}{$\mathbf{2}$ Prior Sternotomies } \\
& HR & P-Value & HR & P-Value \\
\hline 90-Day & $3.23[1.36-7.66]$ & 0.008 & $2.24[0.71-7.09]$ & 0.2 \\
1-Year & $3.23[1.61-6.45]$ & 0.001 & $2.22[0.85-5.76]$ & 0.1 \\
5-Year & $1.58[0.95-2.64]$ & 0.08 & $1.72[0.89-3.32]$ & 0.1 \\
\hline
\end{tabular}


Table 4

Complications Stratified by the Number of Prior Sternotomies

\begin{tabular}{|c|c|c|c|c|}
\hline Variable & 0 Prior Sternotomies & 1 Prior Sternotomy & $\geq 2$ Prior Sternotomies & P-Value * \\
\hline Length of stay (days) & 12 [9-17] & 14 [10-24] & $12[9-25]$ & $0.001^{a}$ \\
\hline ICU LOS (days) & $4.2[2.8-7.0]$ & $5.4[3.3-9.9]$ & $7.5[3.5-16.6]$ & $0.002^{a, b}$ \\
\hline Cardiac reoperation (\%) & $19 / 159(12.0 \%)$ & $75 / 187(40.1 \%)$ & $12 / 35(34.3 \%)$ & $<0.001^{a, b}$ \\
\hline Drug-treated infection prior to discharge $(\%)$ & $13 / 257(5.1 \%)$ & $41 / 263(15.6 \%)$ & $5 / 58(8.6 \%)$ & $<0.001^{a}$ \\
\hline Drug-treated rejection prior to discharge $(\%)$ & $22 / 126(17.5 \%)$ & $16 / 137(11.7 \%)$ & $1 / 30(3.3 \%)$ & 0.1 \\
\hline Cerebrovascular accident $(\%)^{* *}$ & $11 / 275(4.0 \%)$ & $25 / 295(8.5 \%)$ & $6 / 61(9.8 \%)$ & $0.049^{a}$ \\
\hline Renal replacement therapy (\%) & $16 / 275(5.8 \%)$ & $49 / 295(16.6 \%)$ & $14 / 61(23.0 \%)$ & $<0.001^{a, b}$ \\
\hline Intraoperative blood products (units) ${ }^{* * *}$ & $10[6-14]$ & $14.5[10-23]$ & $15[10-22.5]$ & $<0.001^{a, b}$ \\
\hline Postoperative blood products (units) ${ }^{* * *}$ & $5.5[2-12.5]$ & $8[2-16]$ & $9[6-20]$ & 0.3 \\
\hline Total perioperative blood products (units) ${ }^{* * * *}$ & $18[11-31]$ & $26.5[17-44]$ & $34[26-43]$ & $0.003^{a, b}$ \\
\hline
\end{tabular}

* P-value determined by ANOVA, Chi-square, or Fisher's exact test

**

Includes permanent and transient

****

Includes packed red blood cells, fresh frozen plasma, and platelets

${ }^{a}$ Cohort 1 significantly different than cohort 2

${ }^{b}$ Cohort 1 significantly different than cohort 3

${ }^{c}$ Cohort 1 significantly different than cohort 4 